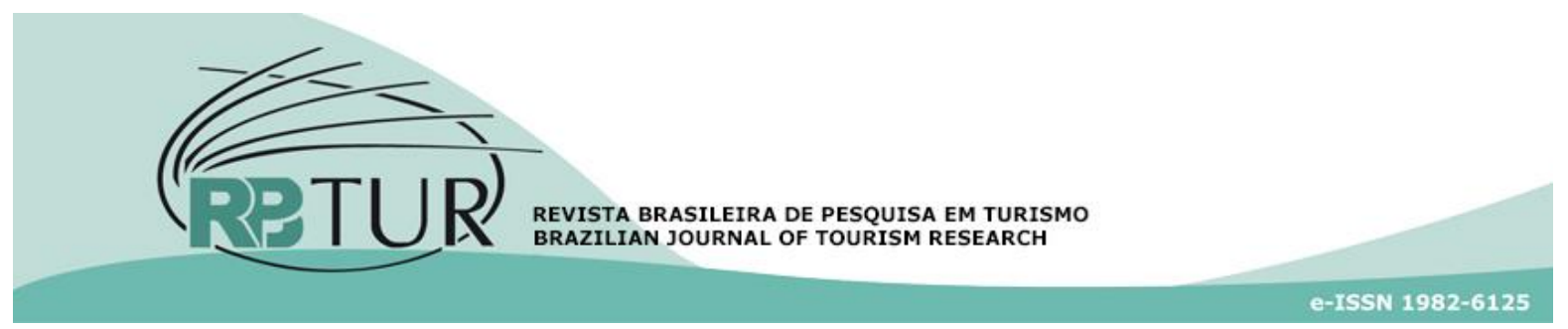

\title{
Artigos
}

\section{Modelo analítico de governança regional de turismo - MAGRET}

\section{Analytical model for regional tourism governance - MAGRET \\ Modelo analítico para la goberanza turística regional - MAGRET}

\section{Cálidon Costa Conceição ${ }^{1}$}

1Universidade do vale do Itajaí (Univali), Florianópolis, Santa Catarina, Brasil.

Palavras-chave:

Modelo analítico.

Governança.

Regionalização do turismo.

\section{Keywords:}

Analytical model.

Governance.

Regionalization of tourism.

\section{Resumo}

No Brasil a estrutura institucional relacionada as organizações contemporâneas que envolvem o cenário das políticas públicas de turismo, atua deliberadamente sobre o formato de instâncias de governanças regionais de turismo a partir de 2004 com o advento do Programa de Regionalização do Turismo (PRT) até os dias atuais. Neste sentido o presente estudo tem como objetivo apresentar o Modelo Analítico de Governanças Regionais de Turismo - MAGRET, que permita compreender as inter-relações dos seus atores nas múltiplas escalas dos poderes público, privado e do terceiro setor. 0 modelo foi aplicado em três regiões turísticas Brasileiras, a Costa Verde e Mar - SC, Região das Hortênsias - RS, e Polo Costa das Dunas - RN. Esses procedimentos perpassaram por etapas de natureza qualitativa e quantitativa, com qualificações exploratórias e explicativas, envolveram a pesquisa bibliográfica, documental e internet (base de dados). As análises utilizaram 14 categorias e 4 dimensões analíticas. As informações foram obtidas junto aos membros efetivos das governanças regionais, assim como dos documentos oficiais tais como (lei/decreto, regimento e estatuto). As análises ocorreram com aplicação do modelo analítico construído com auxílio das categorias e dimensões analíticas. 0 modelo foi aplicado através do uso da espiral de análise construída para compreender a gestão das governanças regionais. Os resultados foram classificados como efetivas e não efetivas. As efetivas são consideradas consolidadas, tendo o cuidado de mantê-las de forma equilibrada. As não efetivas, devendo ser aprimoradas, utilizando sempre a base das dimensões que apontaram quais as categorias necessitam de maior atenção.

\section{Abstract}

In Brazil, the institutional structure related to contemporary organizations that involve the tourism public policy scenario deliberately acts on the format of regional tourism governance bodies from 2004 with the advent of the Tourism Regionalization Program (PRT) until the present day. current. In this sense, this study aims to present the Analytical Model of Regional Governments of Tourism - MAGRET, which allows to understand the interrelationships of its actors in the multiple scales of public, private and third sector. The model was applied in three Brazilian tourist regions, Costa Verde and Mar - SC, Hortênsias - RS, and Polo Costa das Dunas - RN. These procedures went through qualitative and quantitative stages, with exploratory and explanatory qualifications, involving bibliographic, documentary and internet research (database). The analyzes used 14 categories and 4 analytical dimensions. The information was obtained from the effective members of the regional governments, as well as from their official documents such as (law / decree, bylaws and bylaws). The analyzes took place with application of the analytical model built with the aid of the analytical categories and dimensions. The model was applied through the use of the analysis spiral constructed to understand the management of regional governance. The results were classified as effective and not effective. The effective are considered consolidated, being careful to keep them in a balanced way. The non-effective ones should be improved, always using the basis of the 
dimensions that indicated which categories need the most attention.

Palabras clave:

Modelo analítico.

Gobernanza.

Regionalización del turismo.

Revisado por pares.

Recebido em: 21/08/2019.

Aprovado em: 12/01/2020.

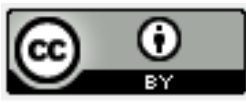

Resumen

En Brasil, la estructura institucional relacionada con las organizaciones contemporáneas que involucran el escenario de la política pública de turismo actúa deliberadamente sobre el formato de los organismos regionales de gobernanza del turismo desde 2004 en adelante con el advenimiento del Programa de Regionalización del Turismo (PRT) hasta la actualidad. actual. En este sentido, este estudio tiene como objetivo presentar el Modelo Analítico de Gobiernos Regionales de Turismo - MAGRET, que permite comprender las interrelaciones de sus actores en las múltiples escalas del sector público, privado y del tercer sector. El modelo se aplicó en tres regiones turísticas brasileñas, Costa Verde y Mar - SC, Hortênsias - RS y Polo Costa das Dunas - RN. Estos procedimientos pasaron por etapas cualitativas y cuantitativas, con calificaciones exploratorias y explicativas, que involucraron investigación bibliográfica, documental e internet (base de datos). Los análisis utilizaron 14 categorías y 4 dimensiones analíticas. La información se obtuvo de los miembros efectivos de los gobiernos regionales, así como de sus documentos oficiales como (ley/decreto, estatutos y estatutos). Los análisis se realizaron con la aplicación del modelo analítico construido con la ayuda de las categorías y dimensiones analíticas. El modelo se aplicó mediante el uso de la espiral de análisis construida para comprender la gestión de la gobernanza regional. Los resultados se clasificaron como efectivos y no efectivos. Los efectivos se consideran consolidados, teniendo cuidado de mantenerlos de manera equilibrada. Las que no son efectivas deben mejorarse, siempre utilizando la base de las dimensiones que indican qué categorías necesitan más atención.

Como citar: Conceição, C.C. (2020). Modelo analítico de governança regional de turismo MAGRET. Revista Brasileira de Pesquisa em Turismo, São Paulo, 14 (2), p. 123-138, maio/ago. http://dx.doi.org/10.7784/rbtur.v14i2.1822

\section{INTRODUÇÃO}

Ao pensar em governança como princípio de gestão no Brasil, é necessário entender que ela é segundo Lastres e Cassiolato (2005), uma forma através da qual indivíduos e organizações, sejam pública ou privada gerenciam seus problemas comuns, cujos interesses não são individuais, e, sim, passam a ser de forma cooperada, em regimes institucionais formais, mas, podendo ser executados também em instituições não formais. Na busca de utilizar a governança no Brasil como prática adequada para seu modo de gestão, seja no setor público, privado ou no terceiro setor, Slomski et al (2008) aponta que seria propício a adoção de conselhos, seja em âmbito municipal, estadual, regional ou federal, para que possa ocorrer a efetivação de um modelo capaz de mensurar sua eficiência no atendimento os princípios constitucionais, pois, estes seriam possíveis caminhos para uma boa governança pública no Brasil.o presente estudo busca demonstrar as possibilidades de análise em uma governança regional de turismo, com a aplicação do Modelo Analítico de Governança Regional de Turismo - MAGRET, que utiliza 14 categorias de análise e 4 dimensões analíticas que são Organização, Relação de poder, Informações e ações, e Resultados. Sendo que as análises podem ser realizadas pelas dimensões de forma individual ou conjunta,

0 estudo da governança realizado nesta pesquisa, teve como foco as governanças regionais de turismo no Brasil, principalmente a partir de 2004 com o lançamento do Plano de Regionalização do Turismo (PRT) "Roteiros do Brasil', mais precisamente no seu terceiro módulo operacional que teceu referências acerca da formalização e institucionalização das Instâncias de Governança Regionais do turismo (IGR).

O referido módulo operacional trata da instância de governança que tem a prerrogativa de "estabelecer uma organização para decidir e conduzir o desenvolvimento turístico de uma região" (BRASIL, 2007, p. 14). Neste sentido, buscou-se compreender como funciona a gestão das regiões turísticas, através de suas institucionalizações, deliberações, planejamentos, ações e resultados, relacionados ao processo de desenvolvimento das governanças regionais de turismo.

Por governança entende-se que é uma forma de política que agrega atores dos setores público, privado e do terceiro setor que atuam conjuntamente para maximizar resoluções de forma cooperadas em prol do desenvolvimento da região, e minimizar ações que não atendem os desejos e anseios dos seus atores e sociedade civil, de forma que venha a prejudicar as atividades realizadas pela governança (Conceição, Anjos \& Anjos, 2019).

Ahrens (2006), assegura que organização da governança são arranjos institucionais, realizam processos 
políticos de implementação, e formulam objetivos políticos coordenados pelos seus diversos atores. Segundo Stocker (1998), estes buscam desenvolver uma série de possibilidades teóricas sobre a governança, informando que elas devem ser inseridas no processo administrativo, pois, refere-se não apenas aos governos, e sim integrantes da sociedade civil.

O conceito sobre governança vem sendo discutido nas mais diversas áreas, o turismo é uma área de estudo que vem utilizando este termo comumente. 0 estudo da governança em turismo é utilizado em pesquisa desde 1993 (Wang \& Li, 2003). Conforme assegura Hall (2011), a governança relacionada a política pública vem sendo utilizada frequentemente na área do turismo.

Vázquez Barquero (2000), define a governança sendo um acordo que ocorre entre seus atores públicos e privados, que permite identificar se as ações são de natureza diversa, facilitando o desenvolvimento e a promoção de forma integrada. A governança segundo Bramwell e Lane (2011), ela não pode ser vista de forma isolada, pois, administra a relação em sociedade, que inclui os grupos sociais buscando influenciar o processo de governança.

Pode-se dizer que a governança vem sendo utilizada como um objeto de estudo nas mais diversas áreas, sendo um termo amplamente utilizando nos círculos acadêmicos e profissionais (Ruschmann, Anjos e Arnhold, 2017). A governança tornou-se um tema importante no cenário da gestão e organização, mas é um termo que pode causar uma compreensão dúbia em relação as políticas públicas, cujas perspectivas são para que haja cooperação, participação e construção coletiva (Seixas \& Mas, 2010).

Ao tratar do tema e conceitos de governança, assim, como o advento de seu uso nas instituições públicas, privadas e terceiro setor, é necessário compreender que seus aspectos estão diretamente relacionados ao envolvimento dos seus atores, pois, estes permitem que ocorra direcionamento de suas ações de forma coesa. Estes atores tem a função de planejar e gerir ações que auxiliem no desenvolvimento de regiões, razão pela qual buscar-se-á compreender a importância e o conceito de governança voltada ao turismo, particularmente de regiões turísticas do Brasil

Neste sentido este estudo versará sobre os conceitos de governança regional de turismo, apontando as análises e modelo construído, de modo que possibilite compreender as governanças regionais por diversos prismas, assim, como apontar seu processo metodológico, tratamento dos dados, análises e resultados.

\section{GOVERNANÇA REGIONAL DE TURISMO}

A governança tem aspectos peculiares que se entrelaçam, pois, o entendimento mais comum que se tem é de auxiliar na gestão e coordenação de atores que sejam interligados por um assunto em comum, que possibilita que este mecanismo contribuía para o seu desenvolvimento, fazendo com que as decisões tomadas dentro da governança sejam a favor de melhorias para todos os envolvidos ligado direta e indiretamente nela.

A governança regional de turismo tem como função primordial atuar em prol de sua região de forma coesa, em que seus atores cooperem e realizem ações conjuntas e transparentes para o melhoramento e desenvolvimento de suas regiões. Entretanto, o fato de existir interesses próprios dos atores em determinadas situações é necessário que eles compreendam que a governança busca demonstrar que o turismo é um negócio coletivo, apontando soluções e informações que elucidam para os seus atoes que a forma de atuação conjunta pode trazer benefícios significativos para seus negócios e interesses particulares.

Olsson (2007) assevera que a governança é um conjunto de atividades que independente de quem a exerça, sendo de autoridades formais ou não, devem ser compartilhadas e aceitas pelos seus atores, pois ela é um sistema que permite a "interdependência entre organizações; a contínua interação entre membros de uma rede; interações que permitem confiança, com regras negociadas; uma significativa autonomia em relação ao Estado, (Rhodes 1997, p. 51). De modo, que os aspectos formais da governança possam alcançar os objetivos políticos, que estão envoltos de uma base referencial que sejam conhecidas por todos seus membros.

A governança de turismo constitui um modelo de gestão imbricado nas relações sociais, na qual seus atores participam das tomadas de decisões sempre de forma conjunta, com o intuito de proporcionar o 
desenvolvimento das atividades turísticas das regiões. Neste sentido, os atores ao aceitar os acordos préestabelecidos nos estatutos, regimentos, leis ou decretos Instâncias de Governanças Regionais (IGRs), possibilitam que haja maior envolvimento em relação as parcerias firmadas, de modo a envolver a integração e cooperação de todos seus atores, tendo o compromisso de discutir e realizar o que possa ser proposto pelas governanças através de seus modelos de gestões (Conceição, 2018).

A governança de turismo regional acontece dentro de um espaço em que as cidades (municípios e distritos) se reconhecem através de atividades turísticas que se complementam ou se correlacionam, com uso da administração pública e privada, que proporciona a governança caminhar em prol do desenvolvimento social e econômico das cidades.

Hall (2011), tece reflexões acerca de como de como as governanças são e por quem são utilizadas, objetivado por modelos propostos que são: o hierárquico, este tipo parte do ideal de governança democrática e governança administrativa, sendo possível diferenciar o poder público do privado; governança de comunidade: pode-se observar que este tipo de governança dar-se-á mediante seu autogoverno, sem a necessidade de intervenção do governo federal, estadual ou municipal, eles tem a capacidade de se autogerir; governança de redes: para este tipo de modelo é necessário que ocorra interação permanente entre os poderes público e privado, para que ocorra a implementação com eficiência de suas políticas públicas e; governança de mercado: que parte do princípio que é o mecanismo mais eficiente para a distribuição dos recursos demandado na governança.

Deste modo Velasco González (2016, p. 508), conceitua governança de turismo sendo um conjunto de redes de "cooperacion y de colaboracion entre los actores publicos y privados que forman parte de la actividad, destacando que su accionar conjunto debe constituir y contribuir a la adecuada gestion turistica en terminos de competitividad y de sustentabilidade". Velasco González (2016) segue afirmando que a governança de turismo se tornou uma nova gestão que pode conduzir os processos de inovação, mudança e fortalecimentos das dinâmicas do turismo que ocorre em determinado espaço, fazendo com que os seus atores públicos e privados tenham a intenção de tomar decisões coletivas.

Zhang, Pine e Lan (2003) tece um comentário sobre a governança no turismo, assegurando que houve mudanças, que durante algum tempo a governança era de preocupação exclusiva do governo, em que ele deveria coordenar as políticas públicas direcionadas à gestão do turismo.

Os diálogos devem ser permanentes entre as partes interessadas, pois para que ocorra crescimento econômico e desenvolvimento cultural e socioambiental da região é necessário que a governança de turismo compreenda que a iniciativa possa surgir de vários setores, sendo os sociais, econômicos, ambientais e políticas, das quais as diferentes iniciativas sejam atribuídas a iniciativa privada, organizações, poder público, possibilitando que haja um processo que envolve os atores e as ações para ultrapassar a atuações individuais, fazendo-as caminhar para a direção voltadas aos grupos, a coletividade (Fernandes \& Coriolano, 2016). Pois a governança mais legítima, é a que nasce no seio de um processo coletivo e não imposta, desta forma buscar-se-á repostas para os questionamentos e desafios coletivos, não subjugando os valores que são compreendidos e compartilhados (Vielajus \& Sauquet, 2007).

\section{PROCEDIMENTOS METODOLÓGICOS}

A operacionalização da pesquisa é constituída de população e amostra, coleta, tratamento e análise de dados, cuja coleta ocorreu através da aplicação de formulários nos membros efetivos da governança de turismo regional, com observações acerca das informações verbais dos respondentes.

A metodologia utilizada para a construção desta pesquisa foi de natureza qualitativa e quantitativa, de modo exploratório e explicativo, com levantamento dos dados através de consulta documentos, leis, relatórios e informações registradas sobre as IGRs e de 47 formulários aplicados junto a 27 representantes do setor público, 14 do setor privado e 6 do terceiro setor, representando uma população de 89 atores, totalizando 51,83\% membros efetivos das Instâncias de Governança Regional: Costa Verde e Mar - SC (15 respondentes), Hortênsias (19 respondentes) e Costa das Dunas - RN (13 respondentes). Crespo (2009), comenta que para se obter uma amostra representativa da população total, são necessários no mínimo de $30 \%$ da população total. Neste caso a amostra foi válida pela percentagem atingida. 
As coletas ocorreram em três momentos, o $1^{\circ}$ realizado em campo na Região das Hortênsias - RS, em novembro de 2016, e por meio on line até julho de 2017. $02^{\circ}$ momento ocorreu na Região da Costa Verde e Mar - SC entre os meses de junho a novembro de 2017, e por meio on line até dezembro de 2017. No $3^{\circ}$ momento ocorreu no Polo Costa das Dunas de forma on line e vídeo conferência no período entre julho de 2017 até fevereiro de 2018. Houve dificuldades em conseguir entrevistas com um número maior de gestores por diversos motivos, como suas agendas sempre apertadas, o próprio receio em ofertar informações por geralmente serem cargos e não gostarem de se expor, e por falta de comprometimento e conhecimento de sua própria atuação à frente a pasta do turismo.

Nesta investigação a coleta dos dados ocorreram em três etapas. A $1^{\circ}$ etapa deu-se na aplicação do formulário com perguntas que tiveram como base as 14 (quatorze) categorias de análise com 44 variáveis construídas a partir do referencial teórico, formando posteriormente quatro dimensões analíticas, que se originaram da sua proximidade teórica sobre temas considerados relevantes acerca das regiões turísticas desta pesquisa.

$\mathrm{Na} 2^{\circ}$ etapa que ocorreu durante a aplicação dos formulários, mesmo sendo estruturados, ocorreu que no momento de sua aplicação foram extraídas informações verbais dos respondentes de forma livre e originais acerca dos temas apontados nos formulários, sendo estas informações devidamente anotados com a anuência dos respondentes.

$\mathrm{Na} 3^{\circ}$ etapa as coletas dos dados ocorreram através dos documentos das governanças regionais de turismo, que foram as leis/decretos, regimento e estatutos, das governanças que as possuíam, pois, estes documentos contribuíram para as análises documentais da pesquisa.

$\mathrm{Na}$ aplicação de todos os formulários foi associada uma entrevista, perfazendo 47 entrevistas aos membros das IGRs. A amostra utilizada foi a entrelaçada, com uso da pesquisa documental (critério), qualitativa (amostra mista) e quantitativa (amostra probabilística intencional). A validação da pesquisa ocorreu com uso do método triangulado, que é considerada a validação mútua dos dados (Brewer \& Hunter. 1989). Segundo Flick (2009), esse tipo de validação discute a pesquisa multimétodos que são aplicadas as fases do processo da pesquisa.

A validação desta pesquisa envolveu dados, qualitativos, quantitativos, estes dados foram tratados e analisados separadamente e apenas agrupados para explicar os resultados finais da pesquisa, na qual deuse a composição de uma validação triangulada. Destarte, deve levar em consideração que a validação é a construção social do conhecimento (Mishler, 1990).

A abordagem quantitativa seguiu as indicações de Fonseca (2002), Richardson (1999) e Diehl (2004). A análise ocorreu como uso da estatística descritiva e a partir dos dados obtidos com a aplicação dos formulários, que utilizou a escala de Likert de sete pontos como medida ordinal (Martins; Theóphilo, 2009; Hair et al, 2005, Reis, 1988). Isto proporcionou obter uma pontuação (frequência/variável), estratificado pelo grau de concordância que foram considerados pelo autor como 1 - discordo totalmente (DT), 2 discordo (D), 3 - discordo parcialmente (DP), 4 - neutra (N), 5 - Concordo parcialmente (CP), 6 - concordo (C) e 7 - concordo totalmente (CT).

Os dados coletados foram tratados mediante a ter sido submetidos a testes de normalidade e de homogeneidade. Crespo (2009) indica que para este tipo de modelagem pode-se eleger tanto o teste de normalidade e/ou teste de homogeneidade para que o modelo possa ser caracterizado como válido. Foram utilizados os testes de normalidade Kolmogorov - Smirnov e o de homogeneidade de variância de Levene. 0 teste de normalidade apresentou diferenças significativas em praticamente todas as categorias (apêndice E), apontando hipóteses alternativas ( $\mathrm{Ha:} \mathrm{P}<0,05)$, fato comum em pesquisas exploratórias, não permitindo apontar a confiabilidade das categorias e dimensões propostas pelo teste de normalidade, mas no teste de homogeneidade, todas as variáveis que compõe as categorias apresentaram hipóteses nulas (Ho: $P>0,05$ ), garantindo a efetividade das categorias e dimensões que compõe a matriz.

Posteriori ao teste deu-se prosseguimento a modelagem com os testes de igualdade de variância de erro de Levene. Para tal teste foi utilizado o Software IBM SPSS Statístics version 21, com aplicação das categorias agrupadas em dimensões, sendo também realizado em todas as dimensões os cálculos de mediana, moda, frequências absoluta e relativa, múltiplas respostas e gerado os gráficos de dispersão, cujos fatores 
significantes foram: regiões turísticas (Costa Verde e Mar, Hortênsias e Costa das Dunas) e tipologia de entidades (setores público, privado e terceiro setor).

Dentre os respondentes houve 26 homens e 21 mulheres, cujo grau de escolaridade ocorreu com a representação de 24 dentre os atores que possuem graduação, 21 pós-graduação e apenas 2 com ensino médio completo. A escolaridade vista nas regiões turística da pesquisa com base nas informações prestadas nos formulários, apresentaram dados que demonstraram que o maior número de atores possui nível de graduação.

A pesquisa qualitativa envolveu os documentos e as informações verbais que foram analisadas a partir da análise de conteúdo de Bardin (1977). As informações contidas nos documentos públicos das regiões turísticas analisadas possibilitaram compreender os objetivos e diretrizes propostas por cada governança regional. 0 procedimento fez com que elas fossem expostas juntamente com suas características de gestão, demonstrando as funções exercidas pelas suas diretorias, além de suas responsabilidades (Michel, 2009).

Os documentos trouxeram informações que remeteram a conhecer desde a sua institucionalização como IGRs, expondo conteúdos que pudessem identificar como foi organizado a sua gestão. Isso possibilitou ter uma base de compreensão sobre o processo de governança empregado sobre cada IGR, visto, que elas são diferentes no seu modo de gestão, mas, com a mesma finalidade, que se traduz no que deveria ser o comprometimento de atuar conjuntamente com seus membros a favor do desenvolvimento e crescimento das regiões turísticas. Foram analisados leis ou decretos, estatutos, regimentos, as características das governanças com base nos documentos.

Estas análises foram realizadas através da utilização das categorias analíticas já elencadas. A análise de conteúdo foi base tanto para a análise documental quanto após a aplicação das entrevistas, visto que foram colhidas para a análise qualitativa informações verbais dos respondentes no momento da aplicação do formulário (Bardin, 1977).

A análise de conteúdo envolve a busca do significado das mensagens emitidas e recebidas através das linguagens, mensagens e as expressões verbais, sendo que os indicadores devem possuir significados indispensáveis para que haja a compreensão dos problemas correspondentes às práticas humanas e a seus componentes psicossociais, portanto, as mensagens podem ser gestuais, orais, escritas, documentais e figurativas (Severino, 2007).

Ao utilizar a análise de conteúdo nesta investigação entendeu-se que ela partiu do pressuposto de que o léxico, uma unidade considerada discreta do texto, assim como um vocábulo constitui uma síntese da realidade de modo condensada, tendo sua frequência o poder de revelar a concepção do emissor, as opções, os valores e as preferências (Chizzotti, 2013).

No decorrer do processo de análise, foi levado em consideração três fases apresentadas por Bardin (1977), que são: pré-análise; exploração do material e; tratamento dos resultados.

A análise qualitativa do estudo se apoiou nas referências já citadas, com o uso das informações verbais obtidas com os respondentes dos formulários, em que posterior a sua resposta apontada nos formulários, teceram comentários de forma suscitas ou naturais acerca do conteúdo expresso no formulário, sendo estas informações registradas não através de gravações, mas de anotações realizadas durante a aplicação do formulário na presença dos respondentes.

Os diferentes métodos que se inter-relacionaram e auxiliaram na análise, oriundos dos dados coletados através das respostas dos formulários (quantitativa), dos documentos oficiais (lei/decreto, regimento e estatuto), e entrevistas com os atores das governanças regionais (qualitativa), permitiu que fosse mensurada a efetividade (ou não efetividade) do processo de gestão das IGRs em relação à dimensão organização.

No intuito em alcançar resultados plausíveis, mensuráveis e factíveis a respeito das governanças regionais de turismo da pesquisa, foi utilizado 14 categorias de análises e 4 dimensões analíticas como demonstrados na subseção posteriori.

\section{CATEGORIAS DE ANÁLISE E DIMENSÕES ANALÍTICAS DA PESQUISA}

A construção das categorias de análise, utilizou-se de diversas referências que auxiliaram no processo de 
investigação e análise desta pesquisa, buscando obter resultados mensuráveis e plausíveis acerca da constituição do Modelo Analítico de Governança Regional de Turismo - MAGRET. Sendo as seguintes categorias: 1) Constituição da governança de turismo regional (legislação); 2) Processo de seleção dos membros da governança de turismo regional; 3) Representatividade entre poderes público e privado na governança de turismo; 4) Relação harmônica e efetiva entre os atores privado e público da governança de turismo; 5) Relação de confiabilidade entre os membros de governança de turismo regional; 6) Informações compartilhadas entre os membros da governança; 7) Envolvimento dos atores no contexto do desenvolvimento socioambiental; 8) Poder de decisão nas propostas e validações das ações da governança de turismo; 9) Qualificação endógena (governança) e exógena (trade e sociedade civil) mediada pela governança de turismo regional; 10) Promoção e comercialização da marca da região turística; 11) Acompanhamento e avaliação das ações da governança de turismo; 12) Benefícios da governança para o turismo regional; 13) Transparência na divulgação das ações e prestação de contas da governança regional de forma pública; 14) Prospecção de projetos e ações a serem realizados pelos atores públicos e privado da governança de turismo regional de modo homogêneo.

Será apresentado de forma suscinta a base referencial e o que foi pretendido averiguar após as entrevistas, sendo este o instrumento de análise qualitativa e quantitativa para a construção da MAGRET:

a) Constituição da governança de turismo regional (legislação): para compreender este tipo de constituição, recorreu-se as considerações de Fratucci (2009); Aleixo, Holanda e Cândido (2012); Yeh (2013); Zhensong, Chaowu e Zhiping (2014) e; Trentin (2016); os quais puderam contribuir com a pesquisa, demonstrando que a constituição de uma governança passa pelas relações de seus atores, com o meio em que convivem, sempre atentos ao cenário em questão, e, ainda, partindo do pressuposto que sua constituição contribui para sua formalização.

b) Processo de seleção dos membros da governança de turismo regional: para entender o processo de escolha dos membros de governança foi necessário entender suas funções como membros desta governança de turismo. Por isso, utilizou-se as prerrogativas de Nóbrega (2012); Meneghel e Tomazzoni (2012); Grun (2014) e; Coutinho (2016)., que tratam a respeito da seleção dos seus membros, destacando a relevância de envolver pessoas que possuem não apenas compromissos coletivos, mas sim que atendam as questões essenciais do turismo, para que ocorra o desenvolvimento da região como um todo.

c) Representatividade entre poderes público, privado e terceiro setor na governança de turismo: para esta categoria as referências que serviram como base foram Dreher e Salini (2010); Nóbrega (2012), Lefebvre (2013), Tomio e Schimidt (2014), apresentam que as relações entre público e privado devem caminhar concomitantemente, para que fique evidenciada a prática de cooperação entre os entes envolvidos, de modo a beneficiar todos os membros da sociedade.

d) Relação harmônica e efetiva entre os atores privado e público da governança de turismo: Luz et al (2009); Zahra (2010); Cunha e Mazaro (2011); Vahl (2011); Meneghel e Tomazzoni (2012); Rodrigues e Souza (2015); salientam que a existência de uma interação de forma salutar entre os atores deum mesmo grupo, buscando a existência da melhor harmonia possível entre os envolvidos.

e) Relação de confiabilidade entre os membros de governança de turismo regional: Rovere (1999), Nóbrega (2015) Scharpf (1992); Rovere (1999); Pechlaner, Volgger e Herntrei (2011); Vahl (2011); Tomio e Schimidt (2014); dizem que a capacidade de confiança que ocorre dentro das organizações devem envolver seus membros nas mais diversas formas, cujo intuito é tornar a entidade cada vez mais colaborativa através das ações desenvolvidas pelos seus atores, tornando-os capazes de formular e implementar políticas coletivas e cooperadas.

f) Informações compartilhadas entre os membros da governança: para esta categoria será utilizado o que foi apresentado por Bordenave (1994); Canclini (1997); Caccia Bava (2001); Ronconi (2011) e; Nóbrega (2013); que discorrem acerca das informações comentando que para sua existência de forma efetiva, elas devem ser democratizadas, e compartilhadas igualmente entre seus membros, vindo à fortalecer a confiança entre todos do grupo. 
g) Envolvimento dos atores no contexto do desenvolvimento socioambiental: os autores Galvani (2004); Cavalcanti (2004); Zhouri (2008), Bodin e Crona (2009), Jacobi e Sinisgalli (2012); Emith (2012); Araújo e Simonian (2016), acreditam que o desenvolvimento sustentável e a proteção do meio ambiente é um dever de todos os envolvidos, tanto do poder público, iniciativa privada, e sociedade civil organizada.

h) Poder de decisão nas propostas e validações das ações da governança de turismo regional: Em relação à tomada de decisão acerca das propostas ou validações das ações, os pesquisadores Rover (2007); Virginio, Delgado e Fortes (2011); Gorni e Dreher (2011); afirmam que são necessárias há existência de decisões em comum acordo entre os atores envolvidos, para que possa funcionar as engrenagens da gestão da governança, cujos anseios devem ser em obter melhores resultados conjuntos, tanto nas propostas a serem feitas, como nas suas validações e ações.

i) Qualificação endógena (governança) e exógena (trade e sociedade civil) mediada pela governança de turismo regional: a qualificação deve ser entendida como uma ação primordial pela governança, sendo considerado um dos elementos relevantes para o desenvolvimento do turismo, em que sua qualificação deva acontecer de forma endógena (dentro da governança regional) e exógena (fora da governança regional), pois, além da qualificação da mão de obra regional, é necessário que os membros da governança sejam qualificados, para que as tomadas de decisões sejam realizadas por atores que detenham o conhecimento sobre os assuntos que são apresentados para a governança regional.

j) Promoção e comercialização da marca da região turística: de acordo com Wielewicki (2012); Pimentel, Pinho e Vieira (2006); Martins (2006); Tamagni e Zanfardini (2009); Kladou e Kehagias (2014), Cox, Gyrd-Jones e Gardiner (2014), a promoção e comercialização de uma marca deve ser primordial para que o destino/região seja conhecido e principalmente comercializado, pois, a marca contribui para o turismo como uma identidade única, propiciando ao visitante que ao conhecer a marca ele identifique o destino como algo interessante, atraente, seguro e que possivelmente retornaria ao destino.

k) Acompanhamento e avaliação das ações da governança de turismo: nesta categoria, Brasil (2007; 2014); Guimarães (2013) Nóbrega (2012; 2015); Farias e Figueiredo (2015), apontam que não basta a existência de planejamento e execução das ações, e comentam que uma das tarefas mais difíceis, possivelmente são as avaliações destes planejamentos e execuções, não obstante, o uso das avaliações permitem que os erros encontrados sejam sanados, proporcionando melhores resultados e otimizando as ações com melhores práticas e resultados.

I) Benefícios da governança para o turismo regional: Dreher, Oliveira e Schimidt (2006); Silva e Maia (2010); Tomio e Schimidt (2014); Sette, Valle e Coutinho (2014); Rodrigues e Souza (2015); Tretim (2016), os benefícios oriundos da governança, sejam pelos aspectos econômicos, sociais ou ambientais, surgem mediante a busca do consenso nas tomadas de decisões em ações que possam nortear maiores benefícios que refletem positivamente na sociedade através da criação de novos empregos, proporcionando maiores rendimentos, assim, como possibilitar ao poder público a pôr em prática políticas públicas que são de desejos da comunidade, favorecendo tanto o residente como o turista.

m) Transparência na divulgação das ações e prestação de contas da governança regional de forma pública: Menezes (2002); Brasil (2002); Ribeiro (2012); Soares, Emmendoerfer, Monteiro (2013); Ribeiro et al (2012) e; Santos, Carniello e Oliveira (2013), salientam que a tomada de decisões em comum acordo entre os poderes público e privado devem acima de tudo estarem claros, tornando necessário que suas decisões e ações sejam conhecidas pelos principais interessados, que são a comunidade em geral.

n) Prospecção de projetos e ações a serem realizados pelos atores públicos, privados e terceiro setor da governança de turismo regional de modo homogêneo: os pesquisadores Beaumont e Dredge (2010); Hall (2011); Raye et al. (2013), tecem referências acerca da importância de se prospectar 
objetivos e caminhos não apenas através de planejamento, mas, sim com ações exequíveis, cujos aspectos são relevantes para que ocorra ações pertinentes ao desenvolvimento da região turística.

Tendo como base as referências e categorias de análise, foi necessário correlacioná-las, de forma que pudessem ser agrupadas em quatro dimensões que contribuíssem para as análises, sendo estas: 1) Organização; 2) Relação de poder; 3) Informações e ações e; 4) Resultados. Conforme representado no quadro 01, com suas respectivas categorias de análise.

Quadro 01 - Dimensões analíticas do MAGRET DIMENSÕES DE ANÁLISE

Organização
1 Constituição da Governança de turismo regional (legislação);

3 Processo de seleção dos membros da governança de turismo regional;

7 Envolvimento dos atores no contexto do desenvolvimento socioambiental.

\section{Relação de poder \\ 3 Representatividade entre} poderes público e privado na governança de turismo; 4 Relação harmônica e efetiva entre os atores privados e públicos da governança de turismo regional;

5 Relação de confiabilidade entre os membros de governança de turismo regional; 8 Poder de decisão nas propostas e validações das ações da governança de turismo regional;

\section{Informações e ações}

8 Informações compartiIhadas de modo efetivo entre os membros das governanças de turismo regional;

11 Acompanhamento da avaliação das ações das governanças regionais de turismo;

13 Transparência na divulgação das ações;

10 Promoção e comercialização da identidade da região turística.
Resultados

9 Qualificação interna (governança) e externa (sociedade civil) mediada pela governança de turismo regional;

12 Benefícios da governança para o turismo regional;

14 Prospecção de projetos e ações a serem realizados pelos atores públicos e privados da governança de turismo regional de modo homogêneo.

Fonte: Autor (2019).

O agrupamento ocorreu com base nas referências e proximidades entre as categorias de forma teórica, cuja intenção foi as inter-relacionar para que seu engendramento ocorresse conforme sua proximidade de organização. Elas contribuíram para a realização das análises desta investigação, e foram necessárias para a elaboração do MAGRET.

As dimensões de análise proposta nesta investigação serviram para analisar os dados por todos os prismas propostos nesta pesquisa, desde seu processo analítico documental, qualitativo e qualitativo. Elas contribuíram para compreender como ocorreu a gestão das governanças regionais de turismo da Costa Verde e Mar - SC, Hortênsia - RS e Polo Costa das Dunas.

\subsection{Testagem da Estrutura da Modelagem Analítica}

As categorias foram inicialmente relacionadas de forma teórica, proporcionando o agrupamento nas dimensões de análises supracitadas, base para dar sequência da modelagem. Para averiguar se o agrupamento nas categorias e nas dimensões se confirmavam, foram realizados testes estatísticos que visou reconhecer a coerência, pertinência e ajuste da teoria ao processo de Análise da Governança Regional de Turismo.

A matriz desenvolvida com base na teoria está representada na figura 01. A figura mostra as quatro dimensões que agruparam as 14 categorias que emergiram das contribuições teóricas sobre Análise da Governança Regional do Turismo. 0 presente modelo foi aplicado nas três governanças regionais de turismo, a Costa Verde e Mar - SC, Hortênsias e Costa das Dunas - RN de forma conjunta, com uso das coletas de dados realizadas junto aos membros efetivos das respectivas governanças.

O modelo gerado traz na sua centralidade as Instâncias de Governanças Regionais - IGRs de turismo, que foram os objetos desta pesquisa. Os resultados alcançados a partir da análise e extração dos dados, permitiu compreender sua gestão, possibilitando entender a composição de sua organização, de modo a aprimorar ou consolidar o processo organizacional, as relações de poderes, as informações e ações, e finalmente os resultados. 
A figura 01 apresenta as categorias e suas dimensões analíticas dentro de um ambiente de análise composta pelas regiões turísticas. Posteriori as realizações das análises são apontadas os seus resultados, na qual houve a necessidade de aplicar classificações denominadas de efetivas e não efetivas. As dimensões classificadas como efetivas diz-se que elas são consolidadas, e não efetivas nominadas de aprimoradas conforme representada na figura 01.

Os critérios para que as governanças regionais sejam consideradas efetivas e não efetivas são apresentadas nas análises aplicadas pela MAGRET através da utilização das abordagens quantitativas e qualitativas (sendo que deverá também mais uma análise específica que são nos documentos oficiais das governanças). Desta forma poderá ser obtido uma melhor compreensão compreender a aplicação do modelo em cada momento da análise.

O decorrer da aplicação do modelo nas governanças regionais de turismo alvo da pesquisa, as análises ocorreram em três momentos que possibilitaram averiguar por diversos prismas a gestão das governanças. O primeiro momento deu-se a partir da aplicação de formulários junto aos membros efetivos das governanças. O segundo momento de análise ocorreu com base nos documentos oficiais das governanças regionais (lei/decreto, regimento e estatuto). O terceiro momento recorreu a utilização das informações verbais dos respondentes dos formulários realizados durante a sua aplicação. aplicação do modelo foi necessária para a sua validação, sendo que a figura 1 apresenta o modelo e a figura 02 a sua aplicabilidade.

Figura 01 - Modelo Analítico de Governança Regional de Turismo - MAGRET

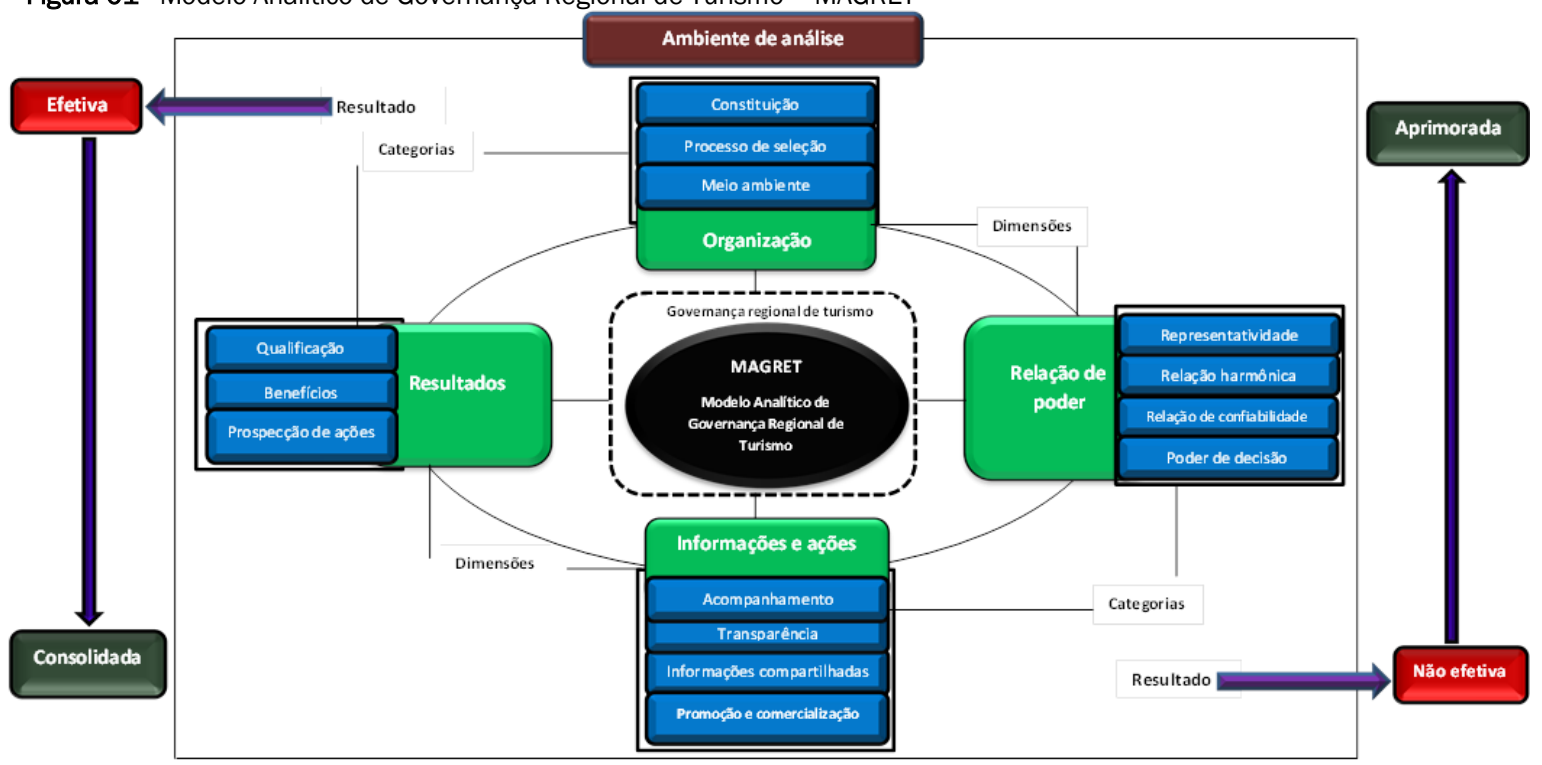

Fonte: Autor (2018)

O modelo traz na sua centralidade as governanças regionais de turismo, objetos a serem analisados e extraídos os possíveis resultados acerca de sua organização, relação de poder, informações e ações e resultados, possibilitando entender a sua composição, de modo a aprimorar ou consolidar conforme o resultado da dimensão.

A aplicação do modelo ocorreu com base nas informações contidas nos dados coletados com aplicação dos formulários em documentos oficiais (lei/decreto, regimento e estatuto), e as informações verbais dos membros efetivos das governanças regionais de turismo no momento da aplicação dos formulários. Estas análises tiveram fundamentalmente a busca de resultados que contribuísse para compreender as governanças regionais da Costa Verde e Mar, Hortênsias e Costa das Dunas a partir do uso da MAGRET

\subsection{Aplicação do Modelo Analítico de Governança Regional de Turismo nas governanças da Costa Verde e Mar - SC, Hortênsias - RS e Costa das Dunas - RN}

A aplicação da Modelo Analítico de Governança Regional de Turismo (MGRT) proporcionou utilizar métodos diferentes, mas, que se complementaram no sentido de obter conteúdo que subsidiassem a compreensão 
das regiões empregando o modelo proposto. Desta forma, a figura 02 demonstra o processo de análise que ocorreu com a espiral de análise de governanças regionais de turismo, e dos componentes que foram usados para alcançar os resultados propostos nesta investigação.

Os dados coletados foram submetidos a testes de normalidade e de homogeneidade. Crespo (2009) indica que para este tipo de modelagem pode-se eleger tanto o teste de normalidade e/ou teste de homogeneidade para que o modelo possa ser caracterizado como válido. Foram utilizados os testes de normalidade Kolmogorov -Smirnov e o de homogeneidade de variância de Levene. 0 teste de normalidade apresentou diferenças significativas em praticamente todas as categorias apontando hipóteses alternativas (Ha: $\mathrm{P}<0,05$ ), fato comum em pesquisas exploratórias, não permitindo apontar a confiabilidade das categorias e dimensões propostas. No teste de homogeneidade, todas as variáveis que compõe as categorias apresentaram hipóteses nulas (Ho: $\mathrm{P}>0,05$ ), garantindo a efetividade das categorias e dimensões que compõe a matriz. Com isso, deu-se prosseguimento de confirmação da modelagem com os testes de igualdade de variância de erro de Levene. Para tal teste foi utilizado o Software IBM SPSS Statístics version 21, com aplicação das categorias agrupadas em dimensões, cujos fatores significantes foram: regiões turísticas (Costa Verde e Mar, Hortênsias e Costa das Dunas) e tipologia de entidades (setores público, privado e terceiro setor).

Os testes estatísticos possibilitaram obter respostas dos agrupamentos das categorias de análise em dimensões analíticas que inicialmente foram realizadas com base na teoria e confirmadas estatisticamente. Os testes de igualdade de variâncias de erro de Levene são apresentados na tabela 03 demonstrando a sua homogeneidade. A tabela 03, apresenta o teste de homogeneidade de Levene das dimensões analíticas da pesquisa, através das categorias que são representadas pelas variáveis apresentadas no formulário de entrevista.

A aplicação do (MAGRET) proporcionou utilizar métodos diferentes, mais de forma agrupada, que se complementaram no sentido de obter conteúdo que subsidiassem a compreensão das regiões empregando o modelo proposto. Desta forma, a figura 02 demonstra o processo de análise que ocorreu com a espiral de análise de governanças regionais de turismo, e dos componentes que foram usados para alcançar os resultados propostos nesta investigação.

As análises propostas a partir de espiral asseguram que ela baseada em modelo e matriz (Bohen, 1998). Ao pensar na espiral como forma de construção de análise desta pesquisa, foi levado em consideração os seus passos de análise que propicia observar cada momento específico de sua análise, pois ela é realizada sequencialmente, sendo inicialmente explicados como foram utilizados cada tipo de instrumentalização.

A utilização das formas de análise realizada pela perspectiva apontada pela espiral contribuiu para encontrar resultados que dessem sustentação científica para construção do modelo proposto, e como assevera Bruner (2006), as ideias devem ser elaboradas e reelaboradas em sucessivas aproximações, permitindo a construção de uma compreensão ampliada.

A figura 02 é representada em forma de espiral, pois, ela tem como prover um metamodelo (modelo/matriz) que pode acomodar diversos processos específicos (Kolb, 1984). Isto significa que ela tem a possibilidade de apresentar as principais características dos métodos vistos anteriormente, adaptando-os as necessidades específicas de desenvolvedores ou às particularidades do que deseja realizar/construir como software, modelo e matriz, cujo esforço é para combinar as vantagens dos conceitos de top-down e bottomup (de cima para baixo ou de baixo para cima), são estratégias que processam informação e ordenamento do conhecimento, que pode ser usado em diversos campos da ciência, incluindo humanísticas, gestão e organização, e teorias científicas (Piaget, 2003, Dubois, 2002).

A opção por utilizar o conceito botton up foi mediante a possibilidade crescente de um resultado, ou seja, a primeira análise que foi a quantitativa permitiu a exploração do modelo de forma homogênea que possibilitou a sua confirmação e a continuidade para sua aplicação. As análises dos documentos oficiais das governanças observaram como as governanças estão realizando sua gestão a partir das suas formalizações (leis/decretos, regimentos e estatutos), e as análises a partir das informações verbais dos respondentes, foi a confirmatória destas análises que utilizou-se das categorias de análise e dimensões analíticas da pesquisa. 
As etapas do modelo em espiral permitem que acomode diversos tipos de abordagens que podem ser voltadas para as especificações que contribua para o desenvolvimento modelo ou matriz (Boehn, 1998).

Figura 02- Espiral de análise da governança regional de turismo

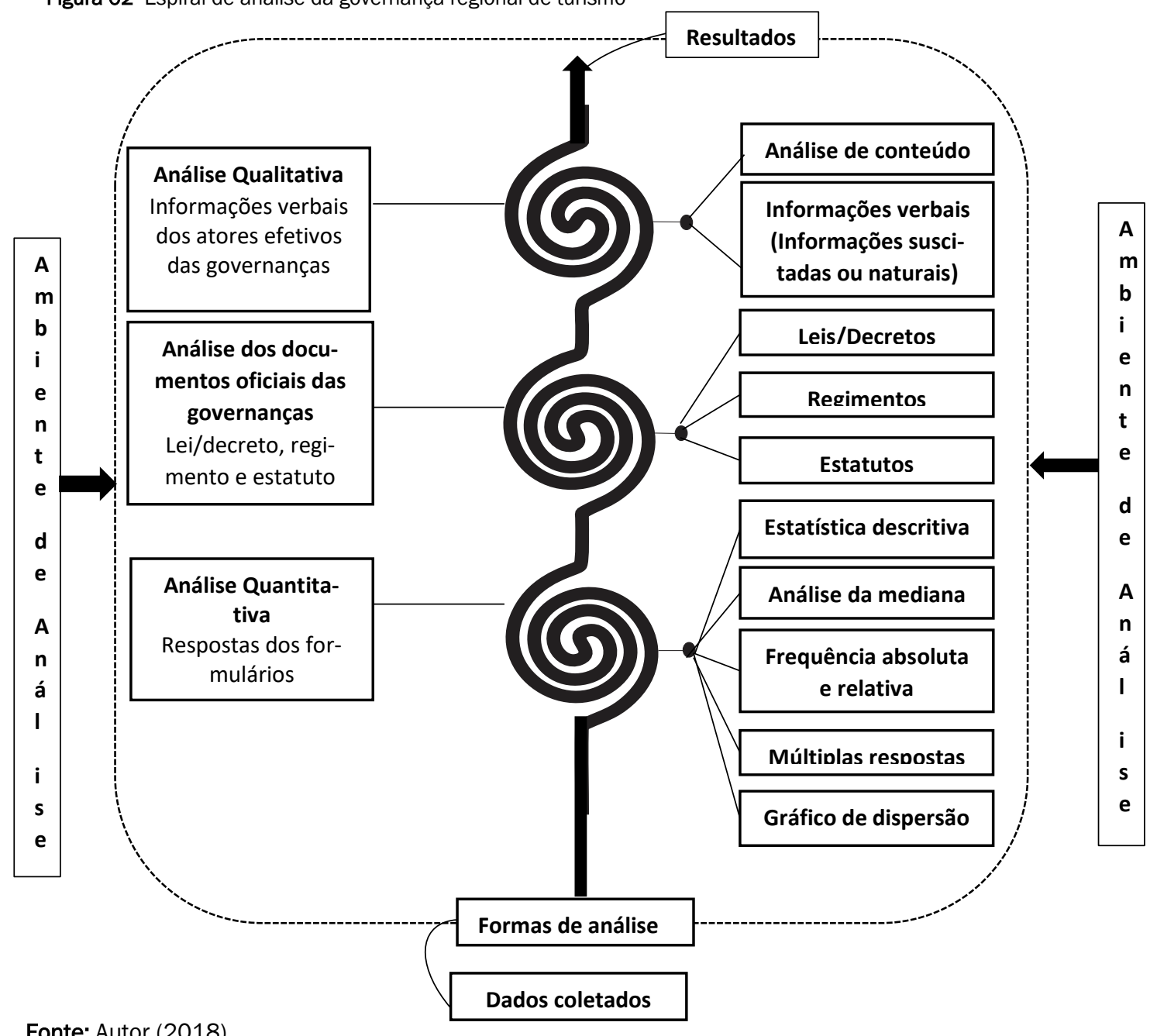

5 ANÁLISES E RESULTADOS DAS RESPOSTAS DOS FORMULÁRIOS, DAS INFORMAÇÕES VERBAIS E DOS DOCUMENTOS OFICIAIS DAS GOVERNANÇAS REGIONAIS DE TURISMO DA COSTA VERDE E MAR - SC, HORTÊNSIAS - RS E COSTA DAS DUNAS - RN

A realização das análises dos dados desta pesquisa ocorreu a partir de alguns aspectos considerados relevantes, que a priori indica os métodos de análises que foram utilizadas nesta investigação, desde que elas fossem da forma mais fidedigna possível sobre as informações apresentadas pelos entrevistados. Segundo Creswell (2014) as análises de dados consistem na preparação e organização dos dados, sejam textos, áudios ou imagens, que permitem realizar a redução dos dados em temas diversos por meio de um processo de condensação dos códigos e criação, assim, como o da representação destes dados em tabelas, figuras ou em uma discussão.

A aplicação do modelo ocorreu com base nas informações contidas nos dados coletados dos formulários, documentos oficiais (lei/decreto, regimento e estatuto), e as informações verbais dos membros efetivos das governanças regionais de turismo no momento da aplicação dos formulários. Estas análises tiveram fundamentalmente a busca de resultados que contribuísse para compreender as governanças regionais da Costa Verde e Mar, Hortênsias e Costa das Dunas a partir do uso do MAGRET.

No processo de compreensão como ocorrem as gestões das governanças regionais de turismo da CVM, RH e PTCD, e posterior aos resultados oriundos da aplicação do MAGRET, possibilitou além de compreender o 
funcionamento da gestão das governanças, determinar quais foram os elementos considerados efetivos e não efetivos conforme a percepção dos seus atores.

\subsection{A dimensão analítica 1 - Organização}

Nas análises da dimensão 1 - organização foram agrupadas três categorias de análise que são a 1 Constituição da Governança de turismo regional (legislação), 2 - Processo de seleção dos membros da governança de turismo regional e, 7 - Envolvimento dos atores no contexto do desenvolvimento socioambiental. Essas categorias tiveram resultados baseados nas repostas dos formulários (quantitativa), com uma classificação que foi vista como não efetiva. Suas leis/decretos, regimento e estatutos (qualitativa/documental), foi classificada como não efetiva. Em relação as informações verbais (qualitativa) a classificação foi considerada também como não efetiva.

\subsection{A dimensão analítica 2 - Relação de poder}

A dimensão analítica 2 - Relação de poder, agrupou as seguintes categorias para realização de suas análises a saber: 3 - Representatividade entre poderes público e privado na governança de turismo; 4 - Relação harmônica e efetiva entre os atores privados e públicos da governança de turismo regional; 5 - Relação de confiabilidade entre os membros de governança de turismo regional; 8 - Poder de decisão nas propostas e validações das ações da governança de turismo regional.

Os resultados expuseram as respostas obtidas com as análises de dados da aplicação dos formulários (quantitativa), e as informações verbais dos membros das governanças (qualitativa) de forma similar, em que trataram este assunto como sendo um tema reconhecido pelos seus membros de forma equacionada, em que os atores sabem da sua importância não somente em realizar ações, mais sim de propô-las e acompanhá-las. Os resultados das análises documentais (qualitativa), apontaram uma classificação como efetiva, mesmo que nem todas as governanças pesquisadas possuíam em seus documentos as informações que tratavam as responsabilidades de cada setor, tanto o público, setor privado e terceiro setor.

\subsection{A dimensão analítica 3 - Informações e ações,}

A dimensão analítica 3 - Informações e ações, trouxe de forma agrupada as categorias 11 . acompanhamento e avaliação das ações da governança de turismo regional; 13 - -transparência na divulgação das ações e prestação de contas da governança regional de forma pública; 6 - Informações compartilhadas entre os membros da governança; 10 - promoção e comercialização da marca da região turística. As categorias aliadas as suas variáveis foram contribuidores das análises acerca da presente dimensão.

No que tange a presença desta dimensão em relação as análises com base nas respostas obtidas com a aplicação dos formulários (quantitativa), a dimensão 3 alcançou a classificação efetiva, devido principalmente a atuação conjunta dos seus atores em relação a transparência das informações de suas ações.

A análise documental (leis/decretos, regimentos e estatutos), aferiram a classificação efetiva, mesmo com a ausência de alguns documentos, mas, os que possuem foram resolutos, trazendo aspectos primordiais para o caminhar salutar da governança regional.

As informações verbais trouxeram elementos que favoreceram as governanças no que diz respeito a sua transparência nas ações das governanças regionais, assim, como as promoções e comercializações que são realizadas para divulgação das regiões turísticas, que perpassam pela validação dos seus membros antes de serem postas ao público. Esta dimensão com base nos aspectos supracitados obtiveram a classificação efetiva.

\subsection{A dimensão analítica 4 - Resultados}

A dimensão analítica 4 - Resultados, utilizou-se das categorias 9 - qualificação interna (governança) e externa (sociedade civil) mediada pela governança de turismo regional; 12 - benefícios da governança para o turismo 
regional; 14 - prospecção de projetos e ações a serem realizados pelos atores públicos e privados da governança de turismo regional de modo homogêneo.

A dimensão analítica resultados que agregou as categorias e suas variáveis acerca deste assunto, teve com resultados através de seus formulários (quantitativa), uma análise considerada efetiva, demonstrando que realizam projetos e ações que possibilitem contribuir para o melhoramento das regiões seja no sentido econômico, ambiental e sociocultal que visam dar subsídios e resultados que possam ser positivos no sentido de sua atuação junto a todos os setores envolvidos com a atividade turística.

As análises documentais apontaram uma deficiência considerável em relação aos seus documentos (lei/decreto, regimento e estatuto), sendo classificada como não efetiva, pois, eles não trouxeram em seus textos como os resultados seriam alcançados ou mensurados, e não houve informação sobre quais seriam as atribuições dos seus atores em relação aos resultados obtidos com a realização das ações das governanças regionais.

A análise com base nas informações verbais (qualitativa), trouxe informações que corroboraram como visto anteriormente na pesquisa quantitativa, que seus atores atuam no sentido de obter resultados que tragam benefícios para todos os seus envolvidos, e que entendem a necessidade de possuir processos de acompanhamento e avaliação, que possam medir as ações realizadas pelos seus atores. Esta dimensão em relação as informações verbais, obteve a classificação efetiva.

\section{IMPLICAÇÕES DOS RESULTADOS}

A dimensão da governança que for classificada como efetiva, ela é considerada consolidada, pois ela já possui um resultado positivo e que agrega possibilidades de subsidiar o desenvolvimento da região, oportunizando com que a governança continue a obter resultados favoráveis no que concerne as suas gestões, perpassando pelos planejamentos, ações e avaliações.

Em relação a dimensão que possui a classificação considerada não efetiva, deve ser aprimorada, pois, esta dimensão com base nas suas categorias pode afetar a gestão da governança regional como um todo, pois algumas etapas, ações e atividades são atreladas umas às outras no que diz respeito a gestão e organização do turismo exercido dentro das governanças regionais de turismo.

A dimensão que foi classificada como não efetiva que neste caso foi a organização, teve como categorias e variáveis referentes a constituição da governança, processo de seleção e envolvimento dos atores no contexto ambiental. Isto traz possibilidades dos seus atores em imprimir esforços para que seja criado condições de melhoramento destas variáveis através de ações e projetos para que a governança venha a obter melhores resultados nos aspectos já identificados e analisados, para que possa ser aprimorada e posteriormente consolidada.

As outras três dimensões foram consideradas efetivas, relações de poder, informações e ações, e resultados. Estas dimensões devem continuar com suas análises continuamente, no intuito de dirimir possíveis problemas que venham a ocorrer, e imprimir novos processos e arranjos institucionais que agreguem valores cada vez mais mensuráveis, para que elas continuem sendo efetivas e consolidadas.

A forma de análise apresentada no MAGRET demonstra que elas podem ser realizadas junto as governanças regionais sem a sequência ordinária das dimensões analíticas, independem a ordem, pois, elas se relacionam a todo momento. 0 que deve ser levado em consideração no momento das análises são as suas classificações (efetiva e não efetiva), no intuito de compreender como elas se inter-relacionam, para que conforme os seus resultados possam realizar ações que sejam condizentes com o que as governanças regionais de turismo necessitam, e almejam alcançar através das suas gestões que são geridas pelos seus atores.

\section{CONSIDERAÇÃOES FINAIS}

A presente pesquisa remeteu-se a um tema que perpassa por caminhos que traduzem o significado de uma construção e participação coletiva, com atuação em rede, com foco nas parceiras, realizações conjuntas de 
atividades inerentes ao cenário turístico que conduzem a busca de melhorias das entidades, empresas, cidades e regiões nos seus diversos aspectos, sociais, econômicos, ambientais e culturas, que tenham a influência direta e indiretamente das políticas públicas de turismo nas suas esferas, federal, estadual e municipal, que são tratadas, planejadas e executadas por governanças regionais de turismo.

Inicialmente para desenvolver o MAGRET, foi necessário elaborar um formulário que objetivasse compreender os aspectos que pudessem ser significativos no sentido de obter resultados mensuráveis e factíveis. O formulário foi composto por 44 variáveis que trataram de diversos temas existentes nas governanças regionais de turismo, essas questões fizeram parte das 14 categorias de análises, sendo estas agrupadas posteriormente em 4 dimensões analíticas que representaram os temas considerados relevantes para analisar as governanças regionais de turismo.

A busca por uma modelo analítico foi principalmente ocasionado por não haver uma região turística no Brasil como modelo exponencial que fosse o parâmetro para as demais, e provavelmente não haveria essa possibilidade de uma governança modelo para um país de dimensões continentais como o Brasil, com peculiaridades e diversidades de governos e gestões estaduais e municipais. Neste sentido, buscou-se elaborar um modelo que permitisse compreender a gestão das governanças regionais, por diversos prismas, desde sua constituição até aos seus resultados, sendo que as governanças podem ser analisadas pelo modelo de forma conjunta ou individualizada. Inclusive mesmo que as governanças sejam distintas, é possível obter uma compreensão com a utilização das suas categorias e dimensões analíticas.

O MAGRET permite que as análises ocorram de uma forma que possa utilizar as quatro dimensões analíticas, ou usá-las de forma individual, isso dependerá do que se deseja compreender em relação a gestão da governança. E deve ser salientado que este modelo pode ser visto como um marco inicial, necessitando de outras pesquisas que possam aplicar em mais regiões turísticas, para que ocorra a compreensão se há necessidade de outras categorias e dimensões analíticas.

Os resultados permitiram compreender de forma analítica como as governanças regionais de turismo se comportam em relação a sua gestão. O MAGRET buscou demonstrar que ele pode ser aplicado para compreender as gestões das governanças regionais de turismo no Brasil de forma conjunta ou individual.

\section{REFERÊNCIAS}

Ahrens, Joachim. (2006). Governance in the process of economic transformation. Draft version.

Bardin, L. (1977). Análise de conteúdo. Lisboa: Edições.

Brasil. Ministério do Turismo. (2007). Módulo operacional 3: instituição da instância de governança regional. Brasília: MTur.

Bramwell, B., Lane, B.(2011) Critical research on the governance of tourism and sustainability. Journal of Sustainable Tourism, 19, 411-421. https://doi.org/10.1080/09669582.2011.580586

Brewer, J., Hunter, A. (1989). Multimethod research: a synthesis of styles. Newbury Park, CA: Sage.

Bruner J. Sobre a teoria da instrução. (2006). São Paulo: PH Editora.

Conceição. Cálidon C. (2018). Modelo de Governança Regional de Turismo - MAGRET. Balneário Camboriú: UNIVALI, 2018. 402F. Tese (Doutorado em turismo e hotelaria) - Programa de Pós-graduação em turismo e hotelaria, Universidade do vale do Itajaí, Balneário Camboriú, Santa Catarina, Brasil.

Conceição, C.C., Dos Anjos, F.A., dos Anjos, G.S.J. (2019) Power Relationship in the Governance of Regional Tourism Organizations in Brazil. Sustainability, 11 (3062), 1-15. https://doi.org/10.3390/su11113062

Creswel, John W. (2014). Investigação qualitativa e projeto de pesquisa: escolhendo entre cinco abordagens. Porto Alegre: Penso.

Crespo, Antonio A. (2099). Estatística fácil. 19 ed. São Paulo. Saraiva.

Diehl, Astor A. Pesquisa em ciências sociais aplicadas: métodos e técnicas. São Paulo: Prentice Hall.

Dubois, Hans F.W. (2002) Harmonization of the European vaccination policy and the role TQM and reengineering could play. Quality Management in Health Care, 10(2): 47-57. https://doi.org/10.1097/00019514-200210020-00009

Fernandes, Laura M., Coriolano, Luzia N. (2015) A governança na política nacional de regionalização do turismo: estudo dos grupos gestores dos destinos indutores do Ceará. Revista Turismo Visão e Ação - Eletrônica, 17(2), 1-33. https://doi.org/10.14210/rtva.v17n2.p247-278 
Flick, Uwe. (2002). Qualidade na pesquisa qualitativa. Porto Alegre: Bookman.

Fonseca, J. J. S. (2002). Metodologia da pesquisa científica. Fortaleza: UEC, 2002.

Hair JR. F. et. al. (2005). Análise multivariada de dados. 5. ed. Porto Alegre: Bookman.

Freund, J. E., Simon, G. A. (2000). Estatística aplicada. 9. ed. Porto Alegre: Bookman.

Hall, C. M. (2011) Policy learning and policy failure in sustainable tourism governance: from first- and second-order to third-order change?. Journal of Sustainable Tourism, s.l, 19 (4), 649-671. https://doi.org/10.1080/09669582.2011.555555

Kolb D. (1984). Experiential learning. Englewwood Cliffs: New Jersey Prentice Hall.

Martins, G. A., Theóphilo, C. R. (2009). Metodologia da investigação científica para ciências sociais aplicadas. São Paulo: Atlas.

Michel, Maria H. (2009). Metodologia e pesquisa científica em ciências sociais. 2. ed. São Paulo: Atlas.

Mishler E. (1990) Validation in Inquiry-Guided Research: The Role of Exemplars in Narrative Studies. Harvard Educational Review, 60(4), 415-443. https://doi.org/10.17763/haer.60.4.n4405243p6635752

Olsson, Giovanni. (2007). Poder político e sociedade internacional contemporânea: governança global com e sem governo e seus desafios e possibilidades. ljuí: Ed. Unijuí.

Piaget J. (2003). Biologia e conhecimento: ensaio sobre as relações entre as regulações orgânicas e os processos cognoscitivos. 4. ed. Petrópolis: Vozes.

Reis, Elizabeth. (1998). Estatística descritiva. Lisboa: Silabo.

Rhodes, R. (2007) Understanding governance: tem years on. Organizationa studies, 28(8), 43-67. https://doi.org/10.1177/0170840607076586

Richardson, Robert, J. et al. (1999). Pesquisa social: métodos e técnicas. 3. ed. São Paulo: Atlas.

Ruschmann, D. V. M., Anjos, F. A. Arnhold Júnior. M.A. (2017) Indicadores de avaliação de governança em destinos turísticos: uma análise de aplicabilidade dos modelos propostos. Applied tourism, 2(1), p. 128-148. https://doi.org/10.14210/at.v2n1.p128-148

Seixas, J., Mas, A.A.I. (2010) Urban Governance in the South of Europe: cultural identities and global dillemmas. Análise Social, Lisboa, 197,771-787

Severino, A. J. (2007) Metodologia do trabalho científico. 23 ed. São Paulo: Cortez.

Stoker, Gerry. (1998) Governance as theory: five propositions. International Social Science Journal, 50, 17-28. https://doi.org/10.1111/1468-2451.00106

Vásquez-Barquero, Antonio. (2000) Desarrollo endógeno y glo - balización. Revista Latinoamericana de estudios urbanos regional Revista Latinoamericana de estudios urbanos regionales - EURE. Santiago, 26 (790). https://doi.org/10.4067/S0250-71612000007900003

Velasco, María. (2016) Entre el poder y la racionalidade: gobierno del turismo, política turística, planificación turística y gestión pública del turismo. Pasos - Eletrônica, 14(3), edição especial, 577-594. https://doi.org/10.25145/j.pasos.2016.14.038

Vielajus, M., Sauquet M. (2007) Corporate responsibility in the multi-stakeholder collaboration in social Governance. In: Private interests and democracy: The Role of Large Enterprises in Democracy and Society. Cracóvia.

Wang, J., LI, T. Review on tourist destination governance in foreign countries. Tourism Tribune. 28(6), 15-25.

Zhang, PineH.Q; R; Lam, T. (2005). Tourism and hotel development in China: from political to economic success. Ho warth: Haworth Hospitality Press.

\section{Informações do autor}

\section{Cálidon Costa Conceição}

Doutor e Mestre em Turismo e Hotelaria pela universidade do Vale do Itajaí - UNIVALI - SC, com doutorado sanduíche pela Universidade de Alicante - Espanha. CEO da APRI Consultoria.

E-mail: calidoncosta@gmail.com

ORCID: https://orcid.org/0000-0002-8665-1589 